3. Heller WM: Time limits on the use of opened multiple-dose vials. Am J Hosp Pharm $1980 ; 37-1610$.

4. Bawden JC, Jacobson JC, Jackson JC, et al: Sterility and use patterns of multiple-dose vials. Am J Hosp Pharm 1982; 39:294-297.

5. Sheth NK, Post GT, Wisniewski TR, et al: Multidose vials versus single-dose vials: A study in sterility and cost-effectiveness. J Clin Microbiol 983; 17:377-379.

6. Longfield RN, Longfield JN, Hyams KC, et al: Multiple-dose vials (MDV): Usage, sterility, and infection control implications, abstracted, Program and Abstracts of the 22 nd Interscience Conference on Antimicrobial Agents and Chemotherapy. Washington, DC, American Society for Microbiology, 1982.

7. Hanley JA, Lippman-Hand A: If nothing goes wrong, is everything all right? Interpreting zero numerators. JAMA 1983; 249:1743-1745.

8. Highsmith AK, Greenhood GP, Allen JR: Growth of nosocomial pathogens in multiple-dose parenteral medication vials. $J$ Clin Microbiol 1982; 15:1024-1028.

John P. Burke, MD Chief, Infectious Disease LDS Hospital Salt Lake City, Utah

\section{Protocols for Hip and Knee Prosthetic Surgeries}

\section{To the Editor:}

We are in the process of upgrading our protocol for hip and knee prosthetic surgeries.

One of our surgeons asked me to obtain samples of policies and procedures for appropriate care of a patient admitted for prosthetic surgery from time of admission to discharge.

This would include proper placement of this patient pre and post surgery, use of the laminar flow room, space suits during surgery, etc.

Any assistance you can provide will be appreciated.

\section{Jean Rowe, RN \\ Yuma Regional Medical Center Yuma, Arizona}

The preceding letter was referred to Harold Laufman, $M D$, for a reply.

Ms. Rowe would have to solicit the policies and procedures manuals from a number of hospitals in order to get protocol on preparatory care of prosthetic surgery patients. There are no standards that are acceptable to all.
Different orthopedic surgeons have different ideas on how to prepare their patients and what to require of the operating room environment. An interesting observation is that such uniformly good results can be obtained with such divergent rituals.

Harold Laufman, MD Emeritus Professor of Surgery Albert Einstein College of Medicine New York, New York

\section{Protective Garments in the Bacteriology Department}

\section{To the Editor:}

As the Infection Control Coordinator of a large hospital, I am writing for any material or information on a problem we are encountering.

Our Bacteriology Department has requested the hospital to furnish a scrub dress or a surgical type gown to wear in the Bacteriology Department since the employees are continually in contact with many microorganisms.

The policy for the Bacteriology Department is to wear a uniform and lab coat while in the department. This coat is to be removed before leaving the area. Even with this precaution, personnel feel that the lab coat is not sufficient protection and that they are carrying organisms home with them.

The head of the laboratory is our pathologist and Chairman of the Infection Committee. He agrees wholeheartedly with the department concerning the scrub dress or gown.

I would appreciate your opinion and any information in regard to infection control in this matter.

Eleanor V. Domm, RN, BS Infection Control Coordinator Nazareth Hospital

Philadelphia, Pennsylvania

The preceding letter was referred to Dieter H.M. Gröschel, MD, for his reply.

One of the safety practices recommended for the handling of biohazardous materials is the protection of the laboratory worker with a coat or a gown. The standard and special safety practices to be published shortly by the Centers for Disease Control and
National Institute of Health ${ }^{1}$ include the wearing of protective garments such as laboratory coats, gowns, smocks, or uniforms while working with biohazardous materials of Biosafety Level 2-parasites, fungi, bacteria and viruses commonly encountered in clinical microbiology specimens. For work with cultures containing or suspected to contain organisms of Biosafety Level 3, eg, Mycobacterium tuberculosis or mild forms of certain fungi causing systemic infection, solid front or wraparound gowns with closure in the back, scrub suits, or coveralls are recommended. In a hospital such garments are best obtained from the operating suite.

The policy of your Bacteriology Department is correct, protective garments should be removed before leaving the laboratory. Coats, gowns, dresses or suits used in the laboratory should be treated as contaminated linen when returned to the hospital or contract laundry for reprocessing.

The safety policy established by your pathologist, who is the responsible safety officer for the laboratories, conforms to sound laboratory safety practices and deserves the support by the infection control personnel as part of the overall employee health program.

\section{REFERENCES}

1. Centers for Disease Control and National Institutes of Health: Biosafety in Microbiological and Biomedical Laboratories. US Dept of Health and Human Services, Public Health Service, in preparation.

Dieter H.M. Gröschel, MD Director of Microbiology University of Virginia Medical Center Charlottesville, Virginia

\section{Source of Biliary Infections}

To the Editor:

We would like to comment on an editorial change made in the abstract of our article, "The source of biliary infections associated with T-tube drainage," in Infection Control, Volume 4, Number 2.

Our article reported data which we felt indicated that a great majority of these infections begin as biliary infec- 
tions and could not be proven to originate from the skin. We stated specifically in our discussion that of all cases of infected bile, in only five was the organism found outside the biliary drainage system before it appeared in the bile, and that in all five of these cases the organism was Staphylococcus epidermidis, an unusual pathogen in this setting. This was accurately stated in the abstract. However, this point is completely obscured by the editorial changes made in other sentences in the abstract, apparently as a result of misunderstanding of our use of the term "descending" infection, apparently taken to mean infection originating in the distal T-tube or on the skin, whereas we actually meant by that term precisely the opposite.

The abstract would have accurately stated our conclusion had it been expressed in the form in which we believe it was submitted, that is, with deletion of the phrase "from the patient's skin" in the 12th line of the abstract and the phrase "or skin" at its very end.

James E. Glasser, MD
William A. Agger, MD
Infectious Disease Section
Department of Internal Medicine
Gundersen Clinic, Ltd.
La Crosse, Wisconsin

James E. Glasser, MD A. Agger, MD La Crosse, Wisconsin

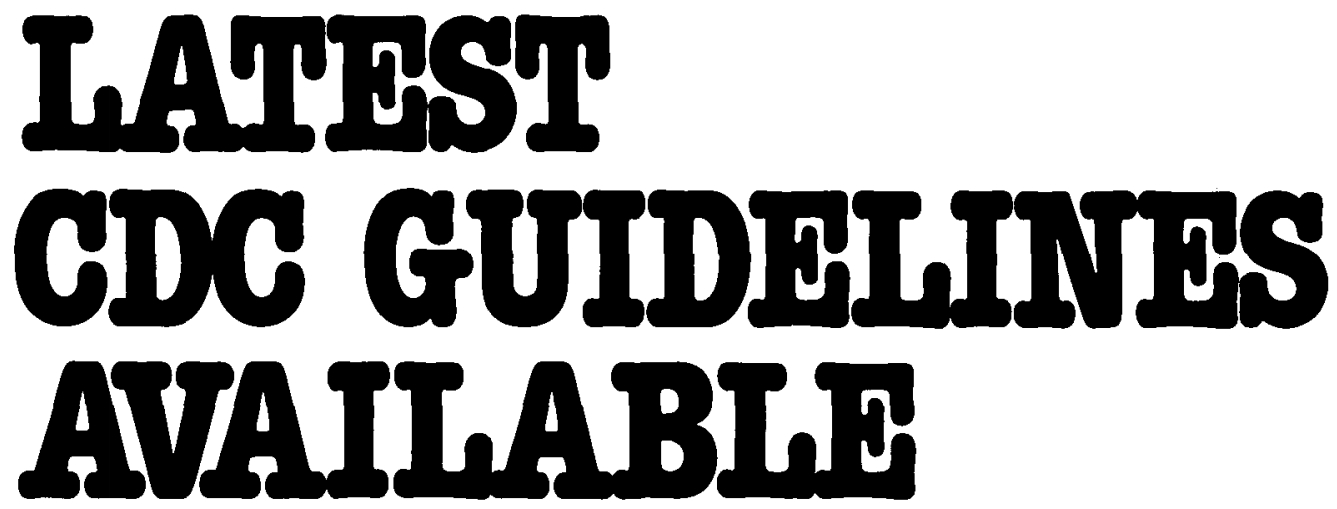

In July 1983, the journal INFECTION CONTROL published the most recent Centers for Disease Control recommendations:

\section{GUIDELINE FOR ISOLATION PRECAUTIONS IN HOSPITALS GUIDELINE FOR INFECTION CONTROL IN HOSPITAL PERSONNEL}

These CDC Guidelines will not be published elsewhere for several months. To receive your own combined copys(s) immediately, return the Order Coupon below with a check or money order for $\$ 5.00$ per copy. (For quantities over 100 copies, call toll-free 800-257-8290, Extension 256 for Special Pricing.)

Don't miss this important opportunity to provide your staff with an integral reference tool for decision-making in your hospital.

Original Publication Made Possible by Stuart Pharmaceuticals

\section{YES!}

Siend me the combined CDC Guidetines immediately: I have specified the number of coppies below: Check (or Money Order) enclosed

No. of Copies — $\times \$ 5.00$ (per copy) $=\$$ TO'TAI.

(. Werke Checks and woney Orders Payuble bo: St.ACK Incorporated) Mail To:

NANIt:

INTTTITION III)RIsis

(:IT)

Send to: SLACK Incorporated 6900 Grove Road, Thorofare, N.J. 08086

Send me subscription information for the journal INFECTION CONTROI.. 


\section{Many Healthcare handwash- ing products contain proven antimicrobial ingredients. However, Calgon's new Acute- Kare Healthcare Personnel Handwash*, with 1\% PCMX, has been shown to be signif- \\ icantly superior in FINAL \\ FORMULATION, to current widely used products in rate and completeness of bacterial kill. And, its emollient- enriched formula is gentle, even after repeated use.}

CALGON ACUTE-KARE' The Most Important Ingredient In Your Healthcare Personnel Handwash Is Not Always The Ingredients...

*As defined in the FDA Panel 1 monograph. Federal Register 1/6/78.

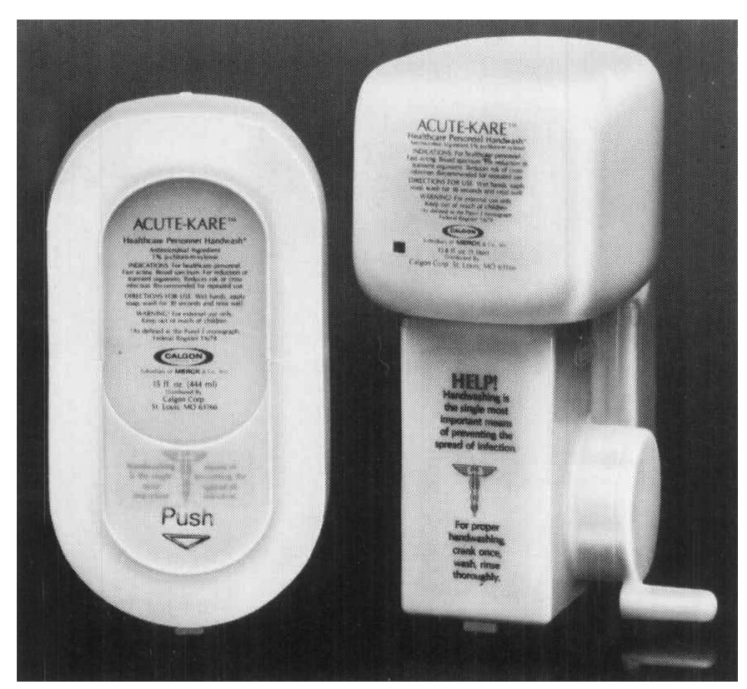

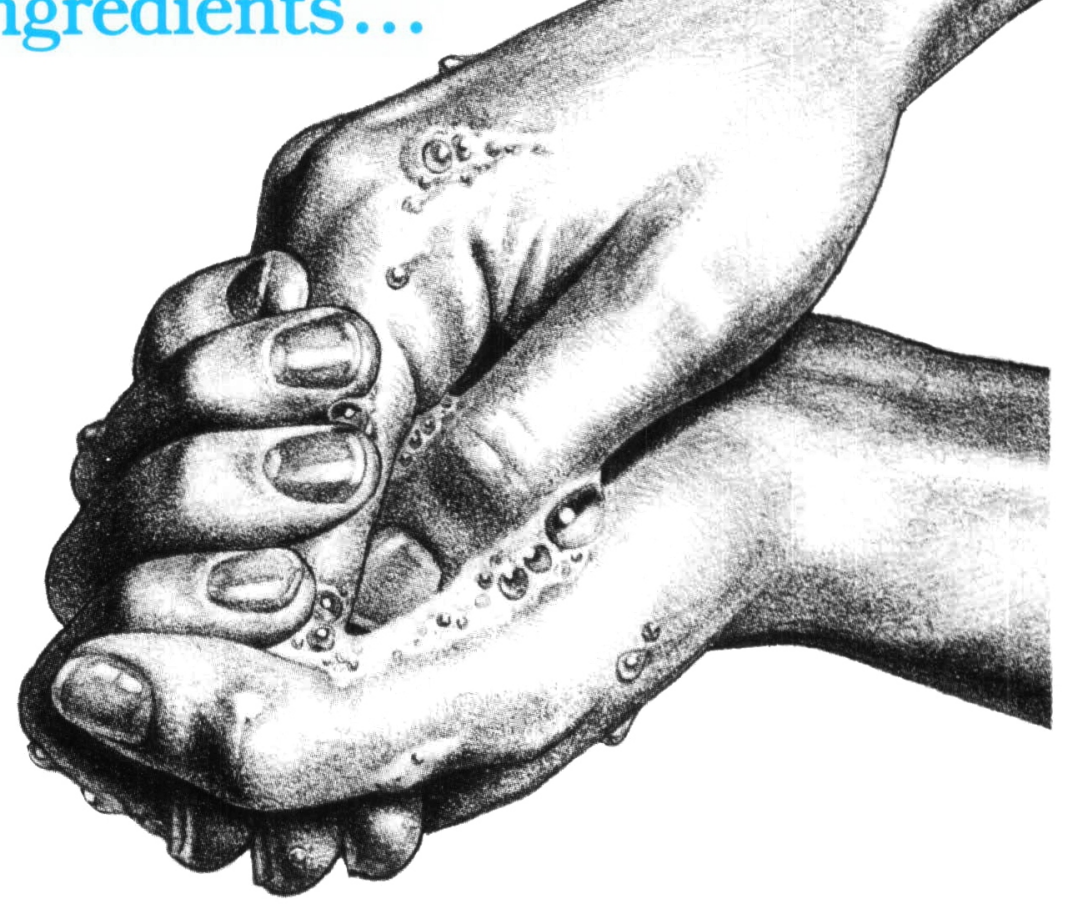

\section{Antimicrobial Protection You Can Count On...}

- Acute-Kare is recommended for high use frequency locations where antimicrobial insurance against contamina tion from transient organisms is required or desirable.

- Contains 1\% PCMX (Para-chloro-meta-xylenol), a broad spectrum antimicrobial ingredient recognized as safe to use in topically applied products.

- Broad spectrum-activity against gram negative and gram positive bacteria and yeast.

- Residual Activity - Handwashing tests following an FDA approved protocol. show a significant reduction in inoculated microorganisms versus a control after 25 wash sequences.

\section{With Gentleness You Deserve...}

- Acute-Kare is non-irritating, even after repeated use.

- Acute-Kare contains unique skin conditioners and emollients.

- Acute-Kare has a pH balanced formula which is compatible with the skin's natural $\mathrm{pH}$.

\section{Call Your Calgon Healthcare Sales Specialist For A FREE Demonstration And Test.}

\section{CALGON}

SUBSIDIARY OF MERCK

$\&$ CO., INC. 